\title{
Low Loss, Finite Width Ground Plane, Thin Film Microstrip Lines on Si Wafers
}

\author{
George E. Ponchak ${ }^{1}$, Alexandros Margomenos ${ }^{2}$, and Linda P. B. Katehi ${ }^{2}$ \\ 1. NASA Glenn Research Center, 21000 Brookpark Rd., MS 54/5, Cleveland, OH 44135, Tel: 216-433- \\ 3504, Fax: 216-433-8705, george.ponchakegrc.nasa.gov \\ 2. University of Michigan, 1301 Beal Ave., 3240 EECS Building, Ann Arbor, MI 48109
}

\begin{abstract}
Si RFICs on standard, $2 \Omega$-cm Si wafers require novel transmission lines to reduce the loss caused by the resistive substrate. One such transmission line is commonly called Thin Film Microstrip (TFMS), which is created by depositing a metallic ground plane, thin insulating layers, and the microstrip lines on the $\mathrm{Si}$ wafer. Thus, the electric fields are isolated from the $\mathrm{Si}$ wafer. In this paper, it is shown through experimental results that the ground plane of TFMS may be finite width and comparable to the strip width in size while still achieving low loss on $2 \Omega$-cm Si. Measured effective permittivity shows that the field interaction with the Si wafer is small.
\end{abstract}

\section{INTRODUCTION}

Si Radio Frequency Integrated Circuits (RFICs) are progressing rapidly into the wireless communication and automobile sensor markets, due in large part to significant improvements in SiGe HBTs. However, RF transmission lines on Si substrates suffer from high loss unless novel transmission lines or high resistivity Si wafers are used [1]. On low resistivity, 0.1 to $10 \Omega-\mathrm{cm}$, Si wafers such as commonly used for CMOS and Bi-CMOS circuits, Thin Film Microstrip (TFMS) has been shown to have low loss [2], and it may be manufactured using standard $\mathrm{Si}$ processing steps to create Si RFICs [3].

A schematic of TFMS is shown in Figure 1. Typically, a large area of the topside of the Si wafer is metallized and this serves as the ground plane for the TFMS. Thus, the ground plane width, G, is very large and may be considered infinite. This assures that there will be no electric field interaction with the $\mathrm{Si}$, wafer and the high loss associated with it. On top of the ground plane, a thin layer of insulating material is deposited to serve as the microstrip substrate. Since polyimide may be deposited in multiple layers of 1 to $20 \mu \mathrm{m}$ thick and it is used for planarization during $\mathrm{Si}$ IC processing, it is often used for the substrate of TFMS lines. Finally, the microstrip circuit is defined on top of the polyimide.

In this paper, we introduce a finite width ground plane TFMS line. Measured attenuation of TFMS show that the ground plane only needs to be 3 to
5 times the strip width, W. Furthermore, measured effective permittivity shows that the finite width ground planes shield the electric fields from the $\mathrm{Si}$ wafer. In the full paper, 2D- Finite Element Method (FEM) analysis will be included. It is believed that these narrow, TFMS lines will enable the production of smaller Si RFICs, which will give them a larger cost advantage compared to GaAs and InP circuits.

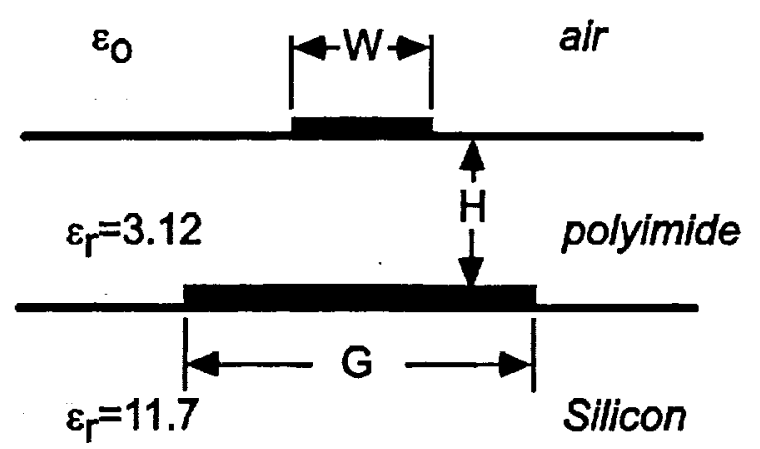

Figure 1: Schematic of Thin Film Microstrip (TFMS).

\section{EXPERIMENT}

To characterize the propagation characteristics of TFMS on Si substrates, test structures are fabricated on a single wafer. A ground plane consisting of a $200 \AA$ $\mathrm{Ti}$ adhesion layer, $1.5 \mu \mathrm{m}$ of $\mathrm{Au}$, and a $200 \AA \mathrm{Cr}$ cap layer is defined on an n-type, 0.5 to $2.5 \Omega$-cm Si wafer. This is followed by spinning on DuPont adhesion promoter and PI-2611 polyimide and curing it at $350 \mathrm{C}$ for 60 minutes. PI-2611 has a relative dielectric constant, $\varepsilon_{\mathrm{T}}$, of 3.12 [4] measured at $1 \mathrm{MHz}$ and a loss tangent of 0.002 [5] measured at $1 \mathrm{kHz}$. The finite width ground planes create a nonplanar surface, which is partially planarized by the polyimide, resulting in the polyimide being $11.25 \mu \mathrm{m}$ thick where there is no ground plane and $11.05 \mu \mathrm{m}$ thick over the ground planes. Therefore, $\mathrm{H}=11.05 \mu \mathrm{m}$ for the TFMS. Ni is used as a hard mask to Reactive Ion Etch (RIE) via holes in the polyimide for topside connection to the ground planes. Finally, a lift off process is to fill the via holes, define the probe pads, and the microstrip lines in 
a single step; $200 \AA \mathrm{Cr}$ and $1.6 \mu \mathrm{m}$ of $\mathrm{Au}$ is used. These dimensions are confirmed through 3D-profiler and SEM measurements, and they also show that surface roughness is small enough to be neglected.

The microwave characterization is performed over the frequency range of 2 to $40 \mathrm{GHz}$ using a HP $8510 \mathrm{C}$ vector network analyzer and GGB Industries RF probes. To extract the attenuation and effective permittivity, $\varepsilon_{e f r}$, of the TFMS, a Thru-Reflect-Line (TRL) calibration routine implemented through the NIST MULTICAL software routine is used. TRL calibration routines use extra data measured during calibration to determine the propagation characteristics of the delay lines. Each set of calibration standards consists of a $5000 \mu \mathrm{m}$ thru line, a short circuit reflect, and delay lines of $6800,7400,9800$, and $15000 \mu \mathrm{m}$ length. The advantage of the MULTICAL TRL calibration routine is that it uses the weighted average of all four-delay lines at each frequency point to increase accuracy. To improve probe placement accuracy, the probe pads are designed to assure probe placement within $15 \mu \mathrm{m}$, which results in a worst case error of 0.6 percent due to probe placement errors.

\section{MEASURED TFMS CHARACTERISTICS}

TFMS lines are characterized for line widths of 23 and $52 \mu \mathrm{m}$. Employing standard microstrip design equations for infinite width ground planes and the polyimide thickness of $11.05 \mathrm{~mm}$, these TFMS lines have a characteristic impedance of 53 and $31 \Omega$ respectively. Ground plane widths, G, of $2 \mathrm{~W}, 3 \mathrm{~W}, 5 \mathrm{~W}$, and $9 \mathrm{~W}$ are characterized. The measured attenuation of these lines is shown in Figure 2. Although TFMS is considered a lossy transmission line, a minimum attenuation of approximately $3 \mathrm{~dB} / \mathrm{cm}$ is achieved, which is lower than similarly sized CPW lines on GaAs or Si with a resistivity greater than $2500 \Omega-\mathrm{cm}$ [REF PONCHAK]. Across the measured frequency spectrum, the attenuation decreases as the ground plane width increases; however, the difference between very wide ground planes ( $\mathrm{G}=9 \mathrm{~W}$ ) and narow ground planes ( $G=2 W$ ) is less than $0.8 \mathrm{~dB} / \mathrm{cm}$ for $53 \Omega$ lines and 0.5 $\mathrm{dB} / \mathrm{cm}$ for $31 \Omega$ lines at $40 \mathrm{GHz}$. Figure 3 shows the measured attenuation at $20 \mathrm{GHz}$ as a function of $\mathrm{G} / \mathrm{W}$ and W/H. It is seen that a ground plane width "greater than $3 \mathrm{~W}$ is required for low attenuation for both the 31 and $53 \Omega$ lines, and wider ground planes do not lower attenuation significantly.

The associated effective permittivity is shown in Figure 4 where it is seen that $\varepsilon_{\text {eff }}$ is greater for narrow ground plane lines; however, $\varepsilon_{\text {eff }}$ does not change for ground plane widths greater than $3 \mathrm{~W}$. While conductor loss in the ground plane is expected to decrease as the ground plane width increases, higher effective permittivity for narrow ground plane lines indicates that some of the increased loss is due to electric fields extending into the Si wafer.

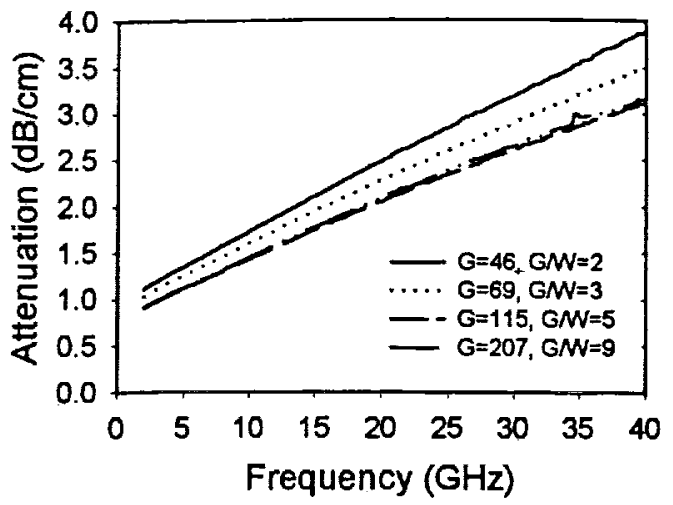

(a)

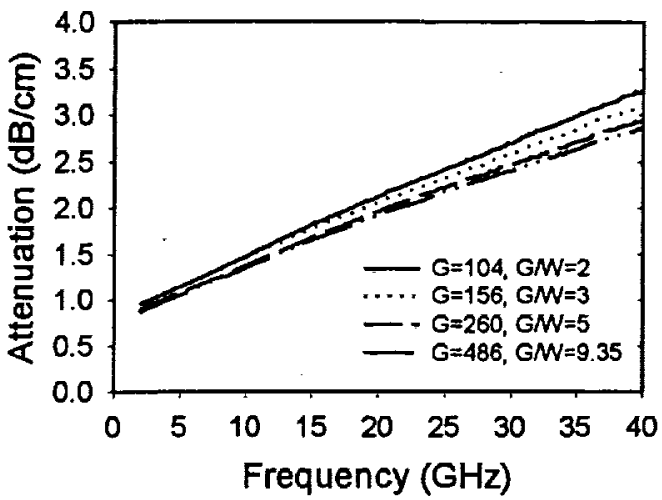

(b)

Figure 2: Measured attenuation of TFMS lines as a function of frequency with (a) $\mathrm{W}=23 \mu \mathrm{m}$ and (b) $\mathbf{W}=\mathbf{5 2} \boldsymbol{\mu m}$.

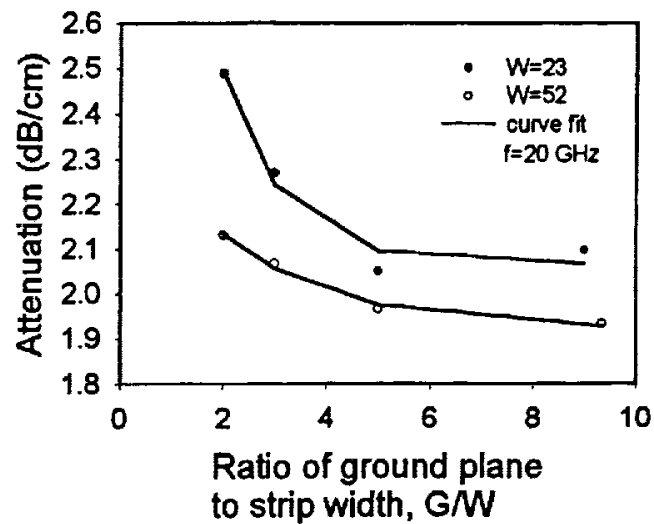

Figure 3: Measured attenuation at $20 \mathrm{GHz}$ of TFMS as a function of the ground plane width to strip width. 


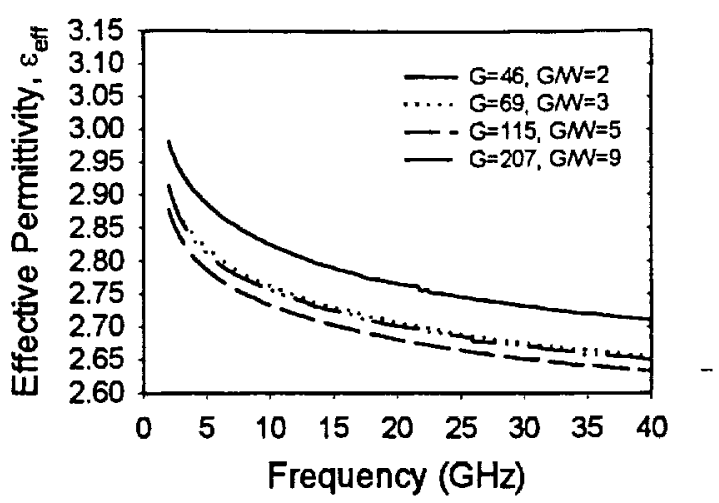

(a)

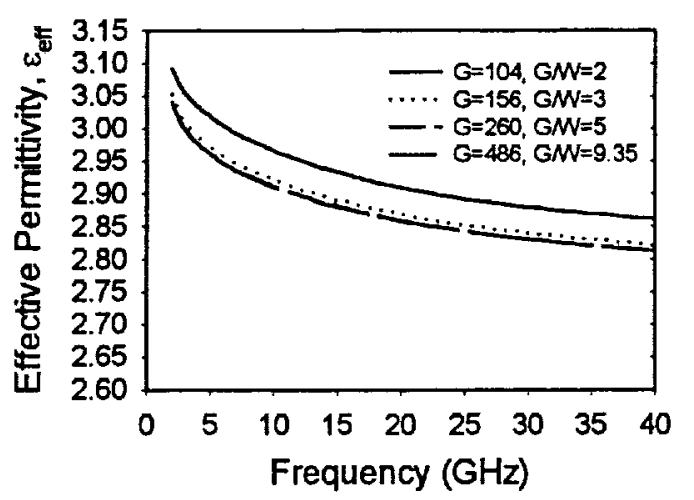

(b)

Figure 4: Measured effective permittivity of TFMS lines as a function of frequency with (a) $W=\mathbf{2 3} \mu \mathrm{m}$ and (b) $\mathbf{W}=\mathbf{5 2} \mu \mathrm{m}$.

\section{CONCLUSIONS}

Through measured propagation characteristics of TFMS lines on $2.5 \Omega-\mathrm{cm}$ Si wafers, it is shown that the ground plane may be reduced to $3 \mathrm{~W}$ without any increase in attenuation. Thus, the area required for the transmission lines is reduced compared to standard TFMS with infinite, or very wide ground planes, and more of the Si wafer is available for active components such as SiGe HBTs and lumped passive elements. Therefore, it should be possible to reduce the size of $\mathrm{Si}$ RFICs.

\section{REFERNCES}

1. G. E. Ponchak, "RF transmission lines on silicon substrates, " 29 th European Microwave Conference Dig., Munich, Germany, Oct. 5-7, 1999, pp. 158-161.

2. G. E. Ponchak and A. N. Downey, "Characterization of thin film microstrip lines on polyimide," IEEE Trans. Components, Packaging, and Manufacturing Tech. -Part B, Vol. 21, No. 2, pp. 171-176, May 1998.

3. I. Toyoda, K. Nishikawa, T. Tokumitsu, $K$. Kamogawa, C. Yamaguchi, M. Hirano, and M.
Aikawa, "Three-dimensional masterslice MMIC on Si substrate," IEEE Trans. Microwave Theory and Tech., Vol. 45, No. 12, pp. 2524-2530, Dec. 1997.

4. J. Leu, H.-M. Ho, J. K. Lee, J. Kasthurirangan, C. N. Liao, and P. S. Ho, "The evaluation of low dielectric constant materials for deep submicton interconnect applications," in Proc. $6^{\text {th }}$ Meeting DuPont Symposium Polyimides Microelectronics, May 1-3, 1995.

5. DuPont Company Pyralin LX data sheet.

6. R. B. Marks, "A multiline method of network analyzer calibration," IEEE Trans. Microwave Theory and Tech., Vol. 39, No. 7, pp. 1205-1215, July 1991. 
